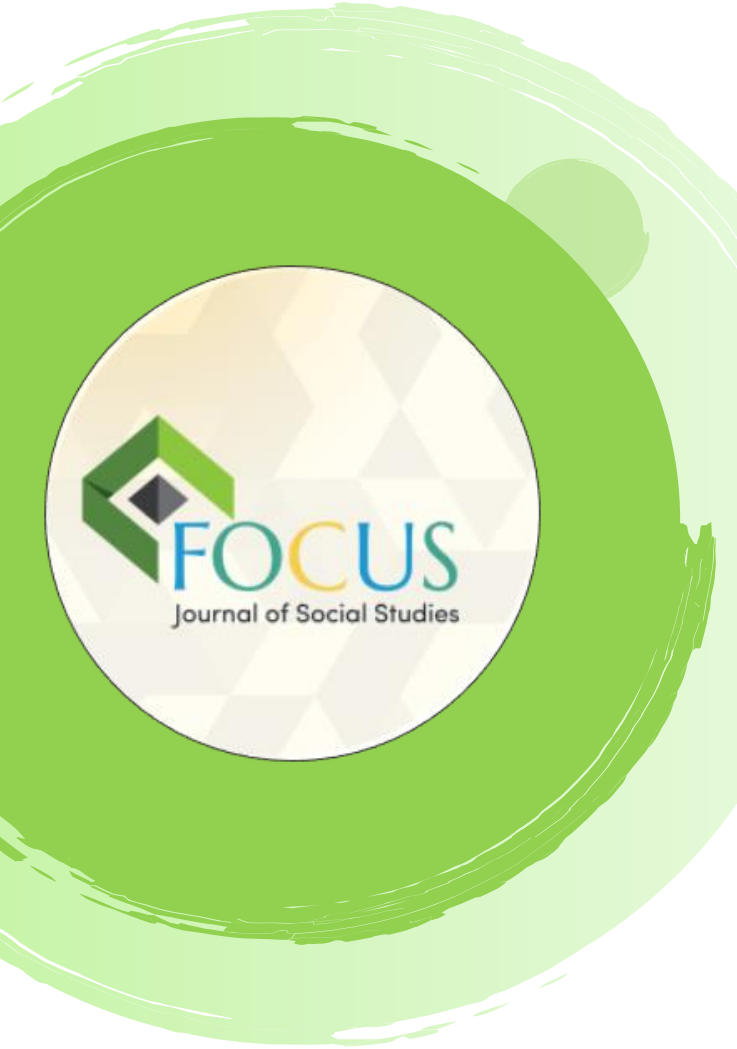

\title{
Analysis of the Influence of Leadership Style, Training, and Physical Work Environment on Motivation and Impact on The Performance of National Cyber and Crypto Agency Employees
}

\author{
Analisis Pengaruh Gaya Kepemimpinan, Pelatihan, dan Lingkungan \\ Kerja Fisik terhadap Motivasi serta Dampaknya terhadap Kinerja \\ Pegawai Badan Siber dan Sandi Negara
}

\section{Sugito Efendi}

Universitas Nasional

Jakarta, Indonesia

sugito_efendi@yahoo.com

\section{Lantika Nandarini}

Universitas Nasional

Jakarta, Indonesia

lantikakaka@gmail.com

\section{DOI}

https://doi.org/10.37010/fcs.v1i1.269

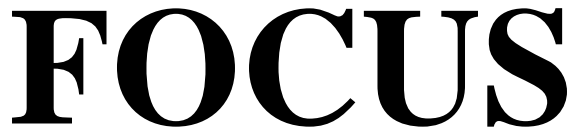

Keywords: leadership style, training, physical work environment, motivation, employee
performance

This study aims to determine the influence of Leadership Style, Training, and Physical Work Environment on Motivation and its impact on The Performance of Employees of National Cyber and Crypto Agency. The analysis method used

in this study is SEM (Structural Equation Model). The results of this study showed that Leadership Style, Training, and Physical Work Environment have a positive and significant effect on Employee Motivation. In addition, Leadership

Style, Training, and Physical Work Environment through Motivation have a positive and significant effect on Employee Performance. Motivation also has a positive and significant effect on Employee Performance.

Abstrak

Penelitian ini bertujuan mengetahui pengaruh Gaya Kepemimpinan, Pelatihan, dan Lingkungan Kerja Fisik terhadap Motivasi serta dampaknya terhadap

Kinerja Pegawai Badan Siber dan Sandi Negara. Metode analisis yang digunakan dalam penelitian ini adalah SEM (Structural Equation Model). Hasil dari penelitian ini menunjukkan bahwa Gaya Kepemimpinan, Pelatihan, dan Lingkungan Kerja Fisik berpengaruh positif dan signifikan terhadap Motivasi Pegawai. Selain itu, Gaya Kepemimpinan, Pelatihan, dan Lingkungan Kerja Fisik melalui Motivasi berpengaruh positif dan signifikan terhadap Kinerja Pegawai. Motivasi pun berpengaruh positif dan signifikan terhadap Kinerja Pegawai.

Kata kunci: gaya kepemimpinan, pelatihan, lingkungan kerja fisik, motivasi, kinerja pegawai

\section{Journal of Social Studies}

\section{Vol. 1 No. 1 \\ FEBRUARI \\ 2020}

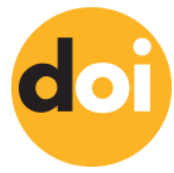




\section{PENDAHULUAN}

Globalisasi merupakan salah satu aspek yang tidak dapat dihindarkan oleh seluruh negara-negara yang ada di dunia. Melalui globalisasi, jarak, waktu, sumber daya, dan perkembangan ilmu pengetahuan menjadi tidak terbatas. Dari waktu ke waktu, globalisasi mengalami perkembangan yang pesat dan memberikan pengaruh terhadap proses pembangunan nasional suatu Negara (Darwin, 2020). Dalam sudut pandang secara administrasi publik, pembangunan nasional yang dikelola oleh pemerintahan tersebut, terdapat peran pegawai Aparatur Sipil Negara (ASN) di dalamnya. Berkaitan dengan hal tersebut, salah satu instansi pemerintah yang mengandalkan peran PNS (ASN) dalam menjalankan tugasnya adalah Badan Siber dan Sandi Negara (BSSN).

Menurut Widiana (2015), kemajuan organisasi sangat bergantung dari Kinerja Pegawai. Pegawai yang berkinerja tinggi akan memberikan kontribusi yang sangat besar dalam mencapai keberhasilan organisasi. Maka perusahaan harus dapat menyusun program yang terstruktur mengenai pengembangan kinerja karyawan agar dapat bersaing dan unggul (Puspitasari \& Darwin, 2021). Oleh sebab itu, BSSN perlu meningkatkan pengelolaan (manajemen) SDM apabila ingin mewujudkan kinerja organisasi yang semakin meningkat dan mencapai target. Secara teori, terdapat beberapa aspek yang memberikan pengaruh terhadap Kinerja Pegawai diantaranya Gaya Kepemimpinan, Pelatihan, Motivasi, dan Lingkungan Kerja. Dalam penelitian ini dilakukan pengkajian mengenai Pengaruh Gaya Kepemimpinan, Pelatihan, dan Lingkungan Kerja terhadap Kinerja Pegawai BSSN dengan Motivasi sebagai variabel intervening.

Kepemimpinan adalah motor penggerak bagi SDM dan sumber daya lainnya. Robbins dan Judge (2017) menyatakan sebuah faktor kunci dalam keberhasilan kepemimpinan adalah Gaya Kepemimpinan dasar individu. Dengan adanya Gaya Kepemimpinan yang tepat, maka SDM dalam organisasi dapat diarahkan untuk melaksanakan pekerjaan sebagaimana mestinya dan berkinerja baik. Zacharatos dan Iverson dalam Noe, et.al (2017) pun menyebutkan bahwa praktik manajemen SDM yang mendukung sistem pekerjaan berkinerja tinggi salah satunya adalah Pelatihan. Pelatihan sebagai salah satu usaha untuk mengurangi/menghilangkan kesenjangan antara kompetensi karyawan dengan yang dikehendaki organisasi. Kompetensi-kompetensi tersebut meliputi pengetahuan, keterampilan, atau perilaku yang sangat penting untuk keberhasilan Kinerja pekerjaan (Noe, et.al, 2017).

Motivasi merupakan salah satu topik yang paling banyak diteliti dalam perilaku organisasi (Robbins dan Judge, 2017). Menurut Mangkunegara dalam Winarno (2019) Kinerja karyawan dipengaruhi oleh faktor Motivasi dan kemampuan. Dalam Astuti dan Iskandar (2015) disebutkan bahwa pada perusahaan memiliki motivasi berbeda dari setiap karyawan di dalamnya. Pemberian Motivasi menjadi salah satu strategi pemberdayaan SDM agar lebih berkinerja.

Widiana (2015) menyebutkan bahwa Lingkungan Kerja yang kondusif memberikan rasa aman dan memungkinkan para pegawai untuk dapat bekerja optimal sehingga Kinerja Pegawai juga tinggi. Hal tersebut mendukung pernyataan Stoner dan Freeman (1996) bahwa Lingkungan Kerja menentukan Kinerj Pegawai, di mana Lingkungan Kerja yang baik (kondusif) akan meningkatkan Kinerja Pegawai. Sedangkan menurut Soedarmayanti (2001), manfaat Lingkungan Kerja adalah menciptakan gairah kerja sehingga Kinerja dan prestasi kerja meningkat.

Menurut Mangkunegara (2004) dalam Widiana (2015) menyebutkan kinerja adalah hasil kerja secara kualitas dan kuantitas yang dicapai oleh seorang pegawai dalam melaksanakan tugasnya sesuai dengan tanggung jawab yang diberikan. Kemajuan sebuah organisasi sangat bergantung dari kinerja karyawan. Pegawai yang berkinerja tinggi akan memberikan kontribusi yang sangat besar dalam mencapai keberhasilan organisasi (Widiana, 2015). 


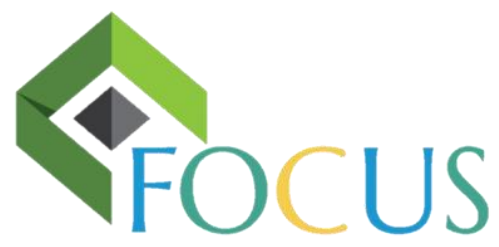

Penelitian terdahulu yang dilakukan oleh Riskianty dan Winarno (2019), Widiastuti (2018), Rondonuwu, Adolfina, Rogi (2017), dan Lumban Raja bahwa Motivasi tidak signifikan berpengaruh terhadap Kinerja Karyawan. Hasil penelitian tersebut tidak sama dengan hasil penelitian yang dilakukan Yasin,et.al (2017), Saeraya dan Saragih (2018), Romansyah dan Winarno (2019), serta Harahap dan Gilang (2019) dihasilkan bahwa Motivasi berpengaruh signifikan terhadap Kinerja Pegawai. Hal tersebut menunjukkan bahwa hasil penelitian terdahulu memiliki hasil yang beragam sebagaimana disebutkan dalam Astuti dan Iskandar (2015) bahwa pada perusahaan memiliki motivasi berbeda dari setiap karyawan di dalamnya.

Oleh sebab itu, dalam penelitian ini variabel Motivasi dijadikan intervening dari pengaruh Gaya Kepemimpinan, Pelatihan, dan Lingkungan Kerja terhadap Kinerja Karyawan sebagaimana saran penelitian oleh Silmiawan dan Syarifuddin (2017), Dwantara dan Gilang (2018), Tambunan dan Iskandar (2015) bahwa diharapkan untuk dapat melakukan penelitian dengan variabel lain yang beragam seperti variabel Kepemimpinan, Pelatihan, dan Lingkungan Kerja yang memungkinkan berpengaruh terhadap Kinerja Pegawai, menggunakan teknik analisis yang lain selain regresi (Citraningtyas dan Ayuningtyas, 2019), dan dilakukan pada perusahaan (organisasi) lainnya agar cakupan menjadi luas (Al Fath dan Saragih, 2019).

Tujuan dilakukan penelitian ini adalah untuk mengetahui pengaruh positif Gaya Kepemimpinan, Pelatihan dan Lingkungan Kerja Fisik secara langsung terhadap Kinerja Pegawai BSSN. Dan juga untuk mengetahui pengaruh positif dan signifikan Motivasi secara langsung terhadap Kinerja Pegawai BSSN. Serta untuk mengetahui pengaruh positif tidak langsung Gaya Kepemimpinan, Pelatihan dan Lingkungan Kerja Fisik terhadap Kinerja Pegawai BSSN melalui variabel Motivasi sebagai variabel mediasi/intervening.

\section{METODE}

Dalam penelitian ini, alat analisis yang digunakan adalah Structural Equation Model (SEM), menggunakan software AMOS versi 22. Sampel yang digunakan sebanyak 200 responden pegawai BSSN dengan teknik penarikan sampling non-probability jenis accidental sampling. Metode pengumpulan data yang digunakan dalam penelitian ini adalah dengan menggunakan kuesioner atau angket yang ditujukan kepada subjek penelitian/responden dan melalui studi pustaka.

\section{HASIL DAN PEMBAHASAN}

\section{Hasil}

Goodness of fit merupakan uji perbandingan antara matriks kovarian sampel dengan matriks kovarian estimasi. Uji ini memiliki tujuan untuk menguji apakah model yang dihasilkan dapat menggambarkan kondisi aktualnya. Kriteria pengujian terdiri dari 3 (tiga) jenis, yaitu absolute fit indices, incremental fit indices, dan parsimony fit indices.

Hasil Pengolahan Data Uji Absolute Fit Indices. Dari hasil pengolahan data, didapatkan bahwa $\chi^{2}$ hitung $<\chi^{2}$ tabel $(204,959<231,484$ dengan sig 0,05 df 179) dan $\mathrm{p}=0,089>0,05$ sehingga H0 diterima atau dengan kata lain matriks kovarians sampel tidak berbeda dengan matriks kovarians estimasi. Dari nilai CMIN didapatkan nilai default model 204,959 dan berada diantara nilai saturated model $(0,000)$ dan independence model $(5979,198)$ sehingga model default sudah baik. 
Berdasarkan pengolahan data didapatkan nilai AGFI 0,892 sehingga model masuk dalam kriteria marginal of fit. Sedangkan nilai NFI 0,966 masuk dalam kriteria model good fit. Nilai TLI 0,995 masuk dalam kriteria good fit. Dari hasil pengolahan tersebut, didapatkan nillai PNFI 0,823 dan PGFI 0,710 berada dalam rentang 0-1 sehingga model fit atau baik. Berdasarkan nilai PNFI 0,823 berada dalam rentang 0,6-0,9 sehingga dapat dikatakan model fit. Dari hasil pengolahan data tersebut, dapat disimpulkan bahwa model struktural fit dengan data yang dikumpulkan dari responden

\section{Pembahasan}

Pendapat responden tentang pengaruh variabel Gaya Kepemimpinan terhadap Kinerja Pegawai adalah sebesar 3,918> 1,96 (nilai Zkritis untuk derajat kepercayaan 95\%) dengan nilai probabilitas (p) sebesar 0,00 $<0,05$ dan nilai koefisien regresi pengaruh langsung sebesar 0,239 (positif), sehingga dapat disimpulkan secara langsung bahwa semakin baik Gaya Kepemimpinan maka Kinerja Pegawai akan semakin kuat begitu juga sebaliknya. Hasil hipotesis mengenai Gaya Kepemimpinan berpengaruh terhadap Kinerja Pegawai tersebut memperkuat dan mempunyai kesamaan dengan hasil penelitian yang dilakukan oleh Agung Widhi Kurniawan (2012) dengan hasil bahwa Gaya Kepemimpinan berpengaruh langsung, positif, dan signifikan terhadap Kinerja Karyawan. Selain itu, penelitian yang dilakukan oleh Al Fath dan Saragih (2019), Citraningtyas dan Ayuningtias (2019), serta Sitorus dan Arwiyah (2019) pun menghasilkan kesimpulan bahwa Gaya Kepemimpinan berpengaruh positif dan signifikan terhadap Kinerja Pegawai. Kesimpulan dari penelitian-penelitian tersebut menunjukkan bahwa Gaya Kepemimpinan akan berdampak terhadap Kinerja Pegawai/bawahannya dan menjadi faktor penting yang memberikan pengaruh terhadap Kinerja seorang pegawai.

Pendapat responden tentang pengaruh variabel Pelatihan terhadap Kinerja Pegawai adalah sebesar 3,435 $>1,96$ (nilai Zkritis untuk derajat kepercayaan 95\%) dengan nilai probabilitas (p) sebesar 0,00<0,05 dan nilai koefisien regresi pengaruh langsung sebesar 0,220 (positif), sehingga dapat disimpulkan secara langsung bahwa Pelatihan secara langsung berpengaruh positif dan nyata terhadap Kinerja Pegawai. Hasil hipotesis mengenai Pelatihan berpengaruh terhadap Kinerja Pegawai tersebut memperkuat dan mempunyai kesamaan dengan hasil penelitian yang dilakukan oleh Tambunan dan Iskandar (2015), Sherly Malini (2020), serta Fauzi,dkk (2019) yang memberikan kesimpulan bahwa variabel Pelatihan merupakan salah satu variabel yang memberikan pengaruh terhadap Kinerja Pegawai. Oleh sebab itu, pemberian kesempatan pegawai untuk mendapatkan Pelatihan dapat digunakan sebagai upaya meningkatkan Kinerja Pegawai.

Pendapat responden tentang pengaruh variabel Lingkungan Kerja Fisik terhadap Kinerja Pegawai adalah sebesar 2,798 > 1,96 (nilai Zkritis untuk derajat kepercayaan 95\%) dengan nilai probabilitas (p) sebesar 0,005 $<0,05$ dan nilai koefisien regresi pengaruh langsung sebesar 0,172 (positif), sehingga dapat disimpulkan secara langsung bahwa semakin baik Lingkungan Kerja Fisik maka Kinerja Pegawai akan semakin kuat begitu juga sebaliknya. Hasil hipotesis mengenai Lingkungan Kerja Fisik berpengaruh terhadap Kinerja Pegawai tersebut memperkuat dan mempunyai kesamaan dengan hasil penelitian yang dilakukan oleh Maddinsyah dan Wahyudi (2017), Kurniadil dan Poerwita (2018), Husen dan Ayuningtias (2018), Hudiya dan Wardhana (2018) yang menghasilkan kesimpulan bahwa Lingkungan Kerja Fisik memberikan pengaruh nyata terhadap Kinerja Pegawai. Oleh sebab itu, Lingkungan Kerja Fisik menjadi salah satu aspek yang harus diperhatikan dalam suatu organisasi karena menjadi salah satu faktor yang ikut menentukan tingkat Kinerja Pegawai dalam organisasi tersebut.

Pendapat responden tentang pengaruh variabel Motivasi terhadap Kinerja Pegawai adalah sebesar 4,491> 1,96 (nilai Zkritis untuk derajat kepercayaan 95\%) dengan nilai probabilitas (p) sebesar 0,00<0,05 dan nilai koefisien regresi pengaruh langsung sebesar 0,386 (positif), sehingga dapat disimpulkan secara langsung 
bahwa semakin baik Motivasi maka Kinerja Pegawai akan semakin kuat begitu juga sebaliknya. Hasil hipotesis mengenai Motivasi berpengaruh terhadap Kinerja Pegawai tersebut memperkuat dan mempunyai kesamaan dengan hasil penelitian yang dilakukan oleh Manikottama, dkk (2019), Rumijati (2017), Saeraya dan Saragih (2018), Romansyah dan Winarno (2019), Harahap dan Gilang (2019) dengan memaparkan kesimpulan bahwa Motivasi berpengaruh positif dan signifikan terhadap Kinerja Pegawai. Motivasi memiliki kontribusi dalam mendorong seorang pegawai untuk melakukan pekerjaannya dengan baik sehingga akan berkinerja dengan baik pula. Oleh sebab itu, organisasi perlu meningkatkan Motivasi pegawai bila ingin membuat Kinerja Pegawai tersebut meningkat atau menjadi lebih baik.

Pendapat responden tentang pengaruh variabel Gaya Kepemimpinan terhadap Motivasi adalah sebesar 7,567> 1,96 (nilai Zkritis untuk derajat kepercayaan 95\%) dengan nilai probabilitas (p) sebesar 0,00<0,05 dan nilai koefisien regresi pengaruh langsung sebesar 0,420 (positif), sehingga dapat disimpulkan secara langsung bahwa semakin baik Gaya Kepemimpinan maka Motivasi akan semakin kuat begitu juga sebaliknya. Hasil hipotesis mengenai Gaya Kepemimpinan berpengaruh terhadap Motivasi pada penelitian ini memiliki kesamaan dan memperkuat hasil dari penelitian yang dilakukan oleh Manikottama, et.al (2019) dan Kurniawan (2012) yang memberikan hasil kesimpulan bahwa Gaya Kepemimpinan berpengaruh secara langsung, positif, dan signifikan terhadap Motivasi. Oleh sebab itu, untuk meningkatkan Motivasi kerja pegawai dapat dilakukan dengan memperbaiki atau menerapkan Gaya Kepemimpinan yang sesuai dan cocok dengan karakteristik pegawai, sehingga nantinya pegawai tersebut dapat lebih termotivasi untuk melakukan pekerjaan yang menjadi tanggung jawabnya tersebut.

Pendapat responden tentang pengaruh variabel Pelatihan terhadap Motivasi adalah sebesar 4,731 > 1,96 (nilai Zkritis untuk derajat kepercayaan 95\%) dengan nilai probabilitas (p) sebesar 0,00<0,05 dan nilai koefisien regresi pengaruh langsung sebesar 0,298 (positif), sehingga dapat disimpulkan secara langsung bahwa semakin tinggi Pelatihan maka Motivasi akan semakin kuat begitu juga sebaliknya. Hasil hipotesis mengenai Pelatihan berpengaruh terhadap Motivasi pada penelitian ini memiliki kesamaan dan memperkuat hasil dari penelitian yang dilakukan oleh Julianry, et.al yang menghasilkan kesimpulan bahwa Pelatihan memberikan pengaruh signifikan terhadap Motivasi. Apabila pegawai diberi kesempatan untuk mendapatkan Pelatihan yang dapat mendukung pelaksanaan pekerjaannya, memudahkan atau mempercepat pekerjaannya maka pegawai tersebut akan termotivasi. Suatu organisasi dapat meningkatkan atau menyediakan fasilitas pemberian Pelatihan kepada para pegawainya untuk meningkatkan Motivasinya dalam melaksanakan tugas dan tanggung jawab yang diberikan kepadanya. Begitu juga dengan pendapat responden tentang pengaruh variabel Pelatihan melalui Motivasi terhadap Kinerja Pegawai adalah sebesar 0,115. Artinya Pelatihan memiliki pengaruh tidak langsung terhadap Kinerja Pegawai BSSN sebesar 0,115. Sehingga dapat disimpulkan bahwa Pelatihan melalui Motivasi berpengaruh positif dan nyata terhadap Kinerja Pegawai.

Pendapat responden tentang pengaruh variabel Lingkungan Kerja Fisik terhadap Motivasi adalah 4,595 $>$ 1,96 (nilai Zkritis untuk derajat kepercayaan 95\%) dengan nilai probabilitas (p) sebesar 0,00<0,05 dan nilai koefisien regresi pengaruh langsung sebesar 0,294 (positif), sehingga dapat disimpulkan secara langsung bahwa semakin baik Lingkungan Kerja Fisik maka Motivasi akan semakin kuat begitu juga sebaliknya. Hasil hipotesis mengenai Lingkungan Kerja Fisik berpengaruh terhadap Motivasi pada penelitian ini memiliki kesamaan dan memperkuat hasil dari penelitian yang dilakukan oleh Manikottama, et.al (2019) menghasilkan kesimpulan bahwa Lingkungan Kerja berpengaruh positif dan signifikan terhadap Motivasi Pegawai, Lumbantoruan (2014) yang menghasilkan kesimpulan bahwa Lingkungan Kerja Fisik berpengaruh positif dan signifikan terhadap Motivasi. Berdasarkan hal tersebut, untuk meningkatkan Motivasi pegawai, suatu organisasi dapat memperbaiki ataupun membuat Lingkungan Kerja Fisik seperti pola penerangan, penataan ruang, pewarnaan bangunan, 
keamanan, dan penyediaan fasilitas dengan baik sehingga dapat meningkatkan Motivasi pegawai dalam organisasi tersebut.

Pendapat responden tentang pengaruh variabel Gaya Kepemimpinan melalui Motivasi terhadap Kinerja adalah sebesar 0,162 (positif). Artinya Gaya Kepemimpinan memiliki pengaruh tidak langsung terhadap Kinerja Pegawai BSSN sebesar 0,162. Sehingga dapat disimpulkan bahwa Gaya Kepemimpinan melalui Motivasi berpengaruh positif dan nyata terhadap Kinerja Pegawai. Hasil hipotesis mengenai Gaya Kepemimpinan melalui Motivasi berpengaruh terhadap Kinerja Pegawai pada penelitian ini memiliki kesamaan dan memperkuat hasil dari penelitian yang dilakukan oleh Manikottama, et.al (2019) yang menghasilkan bahwa Gaya Kepemimpinan berpengaruh signifikan terhadap Kinerja Pegawai melalui Motivasi. Kepemimpinan dianggap dapat meningkatkan Motivasi dari para karyawan sedangkan Motivasi berperan penting dalam peningkatkan kinerja karyawan.

Pendapat responden tentang pengaruh variabel Lingkungan Kerja Fisik melalui Motivasi terhadap Kinerja Pegawai adalah sebesar 0,113. Artinya Lingkungan Kerja Fisik memiliki pengaruh tidak langsung terhadap Kinerja Pegawai BSSN sebesar 0,113. Sehingga dapat disimpulkan bahwa Lingkungan Kerja Fisik melalui Motivasi berpengaruh positif dan nyata terhadap Kinerja Pegawai. Hasil hipotesis mengenai Lingkungan Kerja Fisik melalui Motivasi berpengaruh terhadap Kinerja Pegawai pada penelitian ini memiliki kesamaan dan memperkuat hasil dari penelitian yang dilakukan oleh Manikottama, et.al (2019) yang menghasilkan bahwa Lingkungan Kerja berpengaruh signifikan terhadap Kinerja Pegawai melalui Motivasi. Peranan lingkungan kerja diketahui memiliki peranan penting dalam peningkatkan motivasi karyawan. Lingkungan Kerja dianggap dapat meningkatkan Motivasi dari para karyawan dan Motivasi berperan penting dalam peningkatkan kinerja karyawan. Hal ini perlu disadari oleh pihak manajemen organisasi guna menjaga serta terus meningkatkan Motivasi dalam bekerja.

\section{PENUTUP}

Penelitian ini menunjukkan bahwa variabel eksogen Gaya Kepemimpinan, Pelatihan, dan Lingkungan Kerja Fisik berpengaruh positif dan signifikan terhadap variabel Intervening Motivasi Pegawai dan Kinerja Pegawai sebagai variabel endogen. Begitu juga dengan variabel Eksogen Gaya Kepemimpinan, Pelatihan, dan Lingkungan Kerja Fisik melalui variabel intervening Motivasi berpengaruh positif dan signifikan terhadap variabel endogen Kinerja Pegawai. Motivasi juga berpengaruh positif dan signifikan terhadap Kinerja Pegawai. Bagi peneliti selanjutnya yang akan mengembangkan penelitian ini, sebaiknya dilakukan kolaborasi dan penambahan variabel lain yang memungkinkan memberikan pengaruh terhadap Kinerja Pegawai seperti variabel budaya organisasi, komitmen, kompensasi, disiplin kerja, dan lain sebagainya sehingga hasil penelitian akan lebih kompleks, bervariasi, dan memperkaya teori yang ada serta dapat memperluas lokus penelitian di instansi lain agar cakupan menjadi luas.

\section{DAFTAR PUSTAKA}

Ahmad Yasin, M. F. (2019). Faktor-Faktor yang Mempengaruhi Kinerja Pegawai Bank BJB Syariah Cabang Bekasi. Aplikasi Manajemen dan Bisnis, Vol. 5 No.2, Mei 2019, 9. 


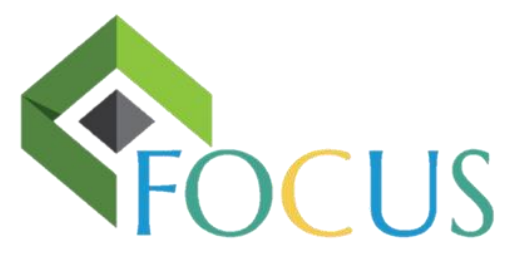

\section{oreñ Ancecess}

Ariviana, R. M. (2019). Pengaruh Lingkungan Kerja terhadap Kepuasan Kerja Karyawan di PT Industri Telekomunikasi Indonesia (Persero) Bandung. e-Proceeding of Management: Vol.6 No.1, 1229.

Arson, B. M. (2020). Pengaruh Gaya Kepemimpinan, Pendidikan dan Pelatihan, dan Lingkungan Kerja terhadap Kinerja Anggota Satuan Polisi Pamong Praja di Kabupaten Kotawaringin Timur . Journal of Environment and Management, 11.

Biro Organisasi dan Sumber Daya Manusia, Sekretariat Utama, Badan Siber dan Sandi Negara. (a.d.). Dislok Pegawai.

Citraningtyas, S. W., \& Ayuningtyas, H. G. (2019). Pengaruh Disiplin Kerja dan Gaya Kepemimpinan Transformasional terhadap Kinerja Pegawai Dinas Pendidikan dan Kebudayaan Kabupaten Cilacap. $e$ Proceeding of Management: Vol.6, NO.2, 2410.

Darwin, M. (2020). The Effect Of Communication Strategy In Marketing 4.0 Purchase Decisions Through Brand Advocacy In Shopee E-Commerce. Jurnal Ilmiah MEA (Manajemen, Ekonomi, \& Akuntansi), 4(2), 375-396.

Dessler, G. (2015). Manajemen Sumber Daya Manusia. Jakarta: Salemba Empat.

Dewi, R. A. (2018). Analisis Pengaruh Kompensasi, Gaya Kepemimpinan, dan Budaya Organisasi serta Dampaknya terhadap Kinerja Pegawai Badan Siber dan Sandi Negara. Jakarta: Universitas Nasional.

Dwantara, C., \& Gilang, A. (2018). Pengaruh Motivasi terhadap Kinerja Karyawan di Unit Research and Development PT Kimia Farma (Persero) TBK Bandung. e-Proceeding of Management : Vol.5, No.1, 1115.

Efendi, S., Guridno, E., \& Kusuma, A. (2020). Analysis of The Influence of Leadership Styles, Compensation, and Career Level on Employee Motivation and Its Impact with Employee Performance in BPPBJ DKI Jakarta Province. Science and Technology Publishing (SCI \& TECH) Vol.4 Issue 11, 519-528.

Fath, M. R., \& Saragih, R. (2019). Pengaruh Gaya Kepemimpinan Transformasional terhadap Kinerja Karyawan pada PT PLN Pusat Pemeliharaan Listrik UWP IV Bandung. e-Proceeding of Management: Vol.6, 1126.

Gilang, A. W. (2018). Pengaruh Lingkungan Kerja Fisik terhadap Kinerja Perusahaan Daerah Bank BPR Gegesik Kabupaten Cirebon. e-proceeding of Management, 3938.

Gumilar, M. A. (2015). Pengaruh Gaya Kepemimpinan dan Motivasi Kerja terhadap Kinerja Pegawai (Studi pada Kantor Wilayah Direktorat Jendral Bea dan Cukai Jawa Barat 2014). e-proceeding of Management, 1530.

Harahap, N., \& Gilang, A. (2019). Pengaruh Motivasi terhadap Kinerja Pegawai Badan Narkotika Nasional Jawa Barat. e-Proceeding of Management: Vol.6 No.2, 4408.

Haryono, S. (2016). Metode SEM untuk Penelitian Manajemen dengan AMOS LISREL PLS. Jakarta: PT Intermedia Personalia Utama.

Huda, A. T. (2018). Pengaruh Kompensasi dan Lingkungan Kerja terhadap Kinerja melalui Motivasi Kerja pada PT pETROIL iNDONESIA. Journal of Economic and Business Aseanomics (JEBA) Vol.3, No.1, Januari-Juni 2018, 23.

Iskandar, A. H. (2015). Pengaruh Pelatihan dan Motivasi terhadap Kinerja Karyawan Div. Human Capital Management PT Inti (Persero) Bandung. e-proceeding Management, 1239.

Juliandi, A., Irfan, Manurung, S., \& Satriawan, B. (2018). Mengolah Data Penelitian Bisnis. Medan: Lembaga Penelitian dan Penulisan Ilmiah Aqli.

Julianry, A., Syarief, R., \& Affandi, M. J. (2017). Pengaruh Pelatihan dan Motivasi terhadap Kinerja Karyawan serta Kinerja Organisasi Kementerian Komunikasi dan Informatika. Jurnal Aplikasi Bisnis dan Manahemen, Vol.3 No.2, 236.

Kepegawaian, P. P. (2019, Januari 27). Manajemen Talenta dalam Konteks Suksesi Kepemimpinan ASN. Gjetur Mei 13, 2020, nga bkn.go.id: bkn.go.id

Koesmono, T. (2003). Peranan Kepemipinan dan Budaya Organisasi terhadap Perilaku Karyawan. EKUITAS, 14. 
Kurniawan, A. W. (2012). Pengaruh Kepemimpinan dan Pengembangan Sumber Daya Manusia terhadap Kepuasan Kerja, Motivasi Kerja, dan Kinerja Karyawan Bank Sulselbar. Ekuitas: Jurnal Ekonomi dan Keuangan, 18.

Kurniawati, D. (2019). Pengaruh Pelatihan terhadap Kinerja Pegawai di Kantor Balai Pelestarian Cgar Budaya (BPCB) DIY. e-proceeding of Management, 1113.

Ma'Mun, S. (2012). Pengaruh Gaya Kepemimpinan, Budaya Organisasi, dan Pengembangan Karier pada Komitmen Organisasi dan Kinerja. Ekuitas: Jurnal Ekonomi dan Keuangan, 19.

Manikottama, R. I., Baga, L. M., \& Hubeis, A. V. (2019). Pengaruh Motivasi, Lingkungan Kerja, dan Kepemimpinan terhadap Kinerja Karyawan PT Satu Visi Edukasi. Jurnal Aplikasi Manajemen dan Bisnis, Vol.5 No.2, 242-252.

Negara, B. K. (2020, Januari 18). Kepemimpinan Transformasional dalam Meningkatkan Kolaborasi Pemimpinan dan Pegawai. Gjetur Mei 12, 2020, nga Badan Kepegawaian Negara: https://www.bkn.go.id/blog/kepemimpinan-transformasional-dalam-meningkatkan-kolaborasipemimpin-dan-pegawai

Negara, B. S. (2019). Laporan Kinerja Sekretariat Utama.

Negara, B. S. (a.d.). Rencana Strategis Sekretariat Utama Tahun 2020-2024.

Noe, R. A. (2014). Manajemen Sumber Daya Manusia, Mencapai Keunggulan Bersaing. Jakarta: Salemba Empat.

Noor, Z. A. (2012). Pengaruh Budaya Organisasi, Komitmen Organisasi, dan Motivasi Kerja terhadap Kepuasan Kerja dan Kinerja Karyawan. Ekuitas: Jurnal Ekonomi dan Keuangan, 14.

Oktaviani, A. D., \& Saleh, B. (2019). Pengaruh Motivasi Kerja terhadap Kinerja Karyawan pada PT Inti Persero Bandung. e-Proceeding of Management: Vol.6 No.1, 1255.

Peraturan BSSN Nomor 5 Tahun 2020 tentang Rencana Strategis BSSN Tahun 2020-2024. (a.d.).

Peraturan Presiden Republik Indonesia Nomor 133 Tahun 2017 tentang Perubahan Atas Peraturan Presiden Nomor 53 Tahun 2017 tentang Badan Siber dan Sandi Negara. . (a.d.).

Perdana, A. R. (2020, Agustus). Analisis Peningkatan Kinerja Karyawan di UP PTSP Kecamatan Makasar dengan Metode Structural Equation Model (SEM). STRING (Satuan Tulisan Riset dan Inovasi Teknologi , 5. No 1 .

Puspitasari, A. S. A., \& Darwin, M. (2021). Effect of Work-Life Balance and Welfare Level on Millennial Employee Performance Through Work Engagement. International Journal of Science and Society, 3(1), 334-344.

Prayitno, B. (2018, Oktober 16). Setiap PNS Berhak Dapat Pengembangan Kompetensi. Gjetur Mei 14, 2020, nga lan.go.id: http://lan.go.id/id/2016-01-05-13-26-55/berita/setiap-pns-berhak-dapat-pengembangankompetensi

Presiden Republik Indonesia Nomor 53 Tahun 2017 tentang Badan Siber dan Sandi Negara. (a.d.).

Priyono. (2007). Pengantar Manajemen. Sidoarjo: Zifitama Publisher.

Priyono. (2010). Manajemen Sumber Daya Manusia. Sidoarjo: Zifitama Publisher.

Priyono. (2010). Sumber Daya Manusia. Sidoarjo: Zifitama Publisher.

Priyono. (2016). Metode Penelitian Kuantitatif. Sidoarjo: Zifatama Publishing.

Purnomo, E. d. (2016). Teori Kepemimpinan Dalam Organisasi. Yayasan Nusantara Bangun Jaya bekerjasama dengan Paguyuban Nusantara Bangkit.

Putra, J. (2020). Pengaruh Gaya Kepemimpinan, Kompetensi, Kompensasi, dan Iklim Organisasi terhadap Kinerja Pegawai Badan Siber dan Sandi Negara. Jakarta: Universitas Nasional.

Radjab, E. d. (2017). Metodologi Penelitian Bisnis. Makasar: Lembaga Perpustakaan dan Penerbitan Universitas Muhammadiyah Makasar.

Raja, F. G. (a.d.). Hubungan Motivasi, Lingkungan Kerja, Kepemimpinan, Disiplin Kerja, dan Kinerja Karyawan PT Asiana Technologies Lestary Jakarta. 


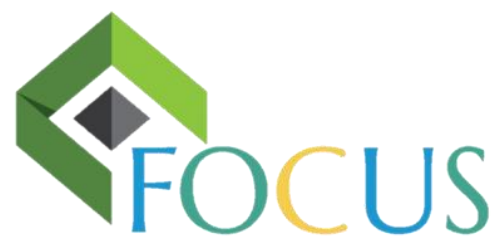

\section{oreu ancecess}

Ramya Inggita Manikottama, L. M. (2019). Pengaruh Motivasi, Lingkungan Kerja,, dan Kepemimpinan terhadap Kinerja Karyawan PT Satu Visi Edukasi . Jurnal Aplikasi Manajemen dan Bisnis, Vol.5 No.2, Mei 2019, 11.

Riskianty, C., \& Winarno, A. (2019). Pengaruh Motivasi Terhadap Kinerja Karyawan Alam Indah Granite Padang. e-Proceeding of Management : Vol.6, No.1, 1262.

Robbins S, d. T. (2017). Perilaku Organisasi. Jakarta : Salemba Empat.

Romansyah, R. R., \& Winarno, A. (2019). Pengaruh Motivasi terhadap Kinerja Karyawan pada PT PLN (Persero) Distribusi Jawa Barat dan Banten. e-Proceeding of Management: Vol.6 No.1, 1271.

Rondonuwu, M. I., Adolfina, \& Rogi, M. H. (2017). Pengaruh Motivasi, Komunikasi, dan Komitmen Karyawan terhadap Kinerja Karyawan di PT Hasrat Abadi Manado. EMBA Vol.5 No.2, 361.

Rumijati, A. (2017). Peran Knowledge Sharing dan Motivasi pada Pengaruh Learning Organization terhadap Kinerja Karyawan. Ekuitas: Jurnal Ekonomi dan Keuangan, 20.

Saeraya, T., \& Saragih, R. (2018). Pengaruh Motivasi Kerja terhadap Kinerja Karyawan di PT PLN (PERSERO) APJ Bandung. e-Proceeding of Management : Vol.5, No.1, 1107.

Sagala, F. N. (2017). Pengaruh Motivasi, Disiplin Kerja, dan Lingkungan Kerja terhadap Kinerja pada Karyawan Perusahaan Daerah Air Minum Kota Cirebon. e-proceeding of Management, 1211.

Sedarmayanti. (2016). Sumber Daya Manusia Reformasi Birokrasi dan Manajemen Pegawai Negeri Sipil. Bandung: Refika.

Silmiawan, R., \& Syarifuddin. (2017). Pengaruh Cross Training dan Motivasi Kerja terhadap Kinerja Karyawan Gumilang Regency Hotel Bandung. e-Proceeding of Management: Vol.4 No.3, 2858.

Sitorus, J. N. (2019). Pengaruh Gaya Kepemimpinan Transformasional terhadap Kinerja Karyawan di PT Cantika Puspa Pesona Jakarta. e-proceeding of Management, 13.

Suryanto, d. (2007, Agustus 2). Kepemimpinan Feodal Masih Terjadi di Instansi Pemerintah. Gjetur Mei 13, 2020, nga Antaranews.com: https://www.antaranews.com/berita/72540/kepemimpinan-feodal-masihterjadi-di-instansi-pemerintah

T.Sipayung, M. A. (2016). Pengaruh Kepemimpinan dan Lingkungan Kerja terhadap Kinerja Karyawan Hotel Bumi Asih Denpasar. e-proceeding of Management, 1257.

tempo. (2017, Maret 17). ASN Wajib Ikuti Pelatihan 20 Jam Per Tahun. Gjetur Mei 14, 2020, nga nasional.tempo.co: https://nasional.tempo.co/read/855732/asn-wajib-ikuti-pelatihan-20-jam-pertahun/full\&view=ok

Tri Mardi Walyono, R. N. (2019). Pengaruh Pelatihan dan Motivasi Kerja terhadap Kompetensi Karyawan serta Implikasinya terhadap Kinerja Karyawan PT Cheil Jedang Indonesia-Jombang Plant. Global, 4.

Utama, S. (2018). Laporan Kinerja Sekretariat Utama. Jakarta: Badan Siber dan Sandi Negara.

Utama, S. (2019). Laporan Indeks Profesionalitas ASN Badan Siber dan Sandi Negara 2019. Jakarta: Badan Siber dan Sandi Negara.

Utama, S. (2019). Laporan Kinerja Sekretariat Utama 2019. Jakarta: Badan Siber dan Sandi Negara.

Waluyo, M. (2016). Mudah Cepat Tepat Penggunaan Tools Amos dalam Aplikasi (SEM). Surabaya: UPN Veteran Jawa Timur.

Widiana, M. E. (2015). Variabel dan Indikator yang Mempengaruhi Komitmen dan Kinerja Organisasi Pemerintahan. Surabaya: Ubhara Manajemen Press.

Widiastuti, S. A. (2018). Analisis Kinerja Karyawan dari Perspektif Motivasi (Studi Kasus Balai Kesehatan Masyarakat Magelang). Upajiwa Vol.2 No.1, 22.

Wike Agustin Prima Dania, U. E. (2012). Pengaruh Budaya Kaizen dan Gaya Kepemimpinan terhadap Kinerja Karyawan dengan Metode Structural Equation Modelling (SEM) Studi Kasus di PT Sierad Produce, Tbk. Sidoarjo . Prosiding Seminar Nasional Manajemen Teknologi XVI, 9.

Winarno, N. F. (2019). Pengaruh Motivasi terhadap Kinerja Karyawan PT Telekomunikasi Indonesia Regional III Jawa Barat Unit Consumer Care. e-Proceeding of Management, 1289. 